\title{
Norovirus outbreaks linked to oyster consumption in the United Kingdom, Norway, France, Sweden and Denmark, 2010
}

T Westrell (therese.westrell@ecdc.europa.eu) ${ }^{1}$, V Dusch $^{2}$, S Ethelberg ${ }^{3}$, J Harris ${ }^{4}$, M Hjertqvist $^{5}$, N Jourdan-da Silva $^{6}$, A Koller $^{7}$, A Lenglet ${ }^{1}$, $M$ Lisby ${ }^{8}$, L Vold 9

1. European Centre for Disease Prevention and Control, Stockholm, Sweden

2. Ministry of Agriculture, France, Paris

3. Statens Serum Institut, Copenhagen, Denmark

4. Health Protection Agency, London, UK

5. Swedish Institute for Infectious Disease Control, Stockholm, Sweden

6. Institut de veille sanitaire, Saint-Maurice, France

7. Norwegian Food Safety Authority, Oslo, Norway

8. Regional Veterinary and Food Control Authority East, Ringsted, Denmark

9. Norwegian Institute of Public Health, Oslo, Norway

Citation style for this article:

Citation style for this article: Westrell T, Dusch V, Ethelberg S, Harris J, Hjertqvist M, Jourdan-da Silva N, Koller A, Lenglet A, Lisby M, Vold L. Norovirus outbreaks linked to oyster consumption in the United Kingdom, Norway, France, Sweden and Denmark, 2010. Euro Surveill. 2010;15(12):pii=19524. Available online: http://

www.eurosurveillance.org/ViewArticle.aspx?Articleld=19524

This paper reports on several simultaneous outbreaks of norovirus infection linked to the consumption of raw oysters. Since January 2010, 334 cases in 65 clusters were reported from five European countries: the United Kingdom, Norway, France, Sweden and Denmark. The article describes the available epidemiological and microbiological evidence of these outbreaks.

\section{Background}

Norovirus in oysters

Oysters are grown in coastal waters of several countries and are considered a delicacy in most parts of the world. Like all bivalve molluscs, they feed by filtering large amounts of water through their gills. In situ studies with bioaccumulation of a virus indicator in oysters have shown that oysters can concentrate viruses up to 99 times compared to the surrounding water [1]. In water contaminated with norovirus, this leads to the accumulation of the virus within the flesh and gut of the oyster. Norovirus has been detected in 5 to $55 \%$ of oysters from Europe and the United States (US) by random sampling at market places and oyster farms [2-4]. The detection of norovirus in oysters follows the same seasonal trend as the norovirus epidemiology in the general population, i.e. norovirus in oysters is generally detected between October and February [1, 12]. Seventy-eight percent of shellfish-related illness from noroviruses in the US between 1991 and 1998 were associated with the consumption of oysters harvested between the months of November and January [1]. Contamination of oyster beds with noroviruses can occur after heavy rains cause flooding, which results in combined sewer overflow or hydraulic overload in sewage treatment plants $[5,13]$. There are also examples of oyster harvesters disposing sewage into oyster-bed waters causing multi-state outbreaks of norovirus in the US [6]. Noroviruses are difficult to remove from oysters through cleansing and also stay infectious even if cleaned[7]. Oysters are often eaten raw, creating the potential for foodborne enteric virus infections.

\section{Outbreaks previously reported \\ in the European Union}

Several norovirus outbreaks linked to the consumption of oysters have been reported in Europe in recent years [5, 8-10]. In a review by Baert et al. (2009), bivalve shellfish accounted for $17.5 \%$ (7/40) of internationally reported foodborne norovirus outbreaks in 2000-2007 [11]. A search of the Rapid Alert System for Food and Feed (RASFF) database (https://webgate.ec.europa. eu/rasff-window/portal/) revealed 19 alert notifications on norovirus findings in oysters and/or norovirus food poisoning associated with the consumption of oysters between March 2006 and March 2010. All of these alerts concerned oysters grown and sold within the European Union (EU) and 17 were reported between the months of January and April, reflecting the season when oysters are considered to be of the best quality.

\section{Current situation (January to March 2010)}

From January to March 2010, the European Centre for Disease Prevention and Control (ECDC) was informed through its Food- and Waterborne Diseases and Zoonoses (FWD) surveillance network about norovirus outbreaks linked to consumption of oysters in five EU/EEA countries: the United Kingdom (UK), Norway, France, Sweden and Denmark. In total 65 small clusters involving 334 cases were reported. Most cases had eaten oysters in restaurants. For the purpose of this article we defined a verified cluster as one where 
(i) evidence was available that cases had consumed oysters within the incubation period (descriptive epidemiology) and (ii) norovirus was identified with reverse transcription RT- PCR (RT-PCR) in oysters from the same batch or from the same harvesting area as the oysters which were consumed by the cases (microbiological evidence). Following these criteria, 27 of the clusters were verified (Table).

\section{Outbreak description}

\section{United Kingdom}

In January 2010, local authorities in the UK notified 22 possible foodborne clusters of gastroenteritis associated with consumption of oysters in restaurants, affecting over 120 people to the Health Protection Agency (HPA). Investigations identified norovirus genogroup I (GGI) and genogroup II (GGII) in stool samples taken from cases in nine of the 22 clusters and in oysters in three of these clusters.

Oysters produced in England, Scotland and Ireland were implicated in the clusters. However, most were sourced from one producer in Ireland. Ireland issued a RASFF alert on 17 February after having detected norovirus in Irish oysters. Control measures taken in Ireland included closure of identified fishing areas and withdrawal of shellfish coming from these areas.

\section{Norway}

In Norway, eight clusters of gastroenteritis involving 39 cases were notified between 22 January and 6 February 2010. Cases became ill after having eaten oysters from one importer distributed to six different restaurants in Oslo. No stool samples were collected. The local food authorities traced back the oysters to one producer from Brittany in France. Two of three incriminated batches were analysed at the Norwegian School of Veterinary Science, and both tested positive for norovirus genogroup I (GGI) and genogroup II (GGII) by RT-PCR. A RASFF alert was issued on 11 February.

\section{France}

Six foodborne clusters of gastroenteritis were notified linking the consumption of oysters originating from the same area in Brittany (1) as the area incriminated in the Norwegian clusters. The French clusters occurred in weeks two to nine 2010, and involved 22 cases. The cases had consumed oysters mainly in restaurants but also in their homes. No stool specimen was available for analysis. Oysters coming from this area were sampled and norovirus was detected. Four additional clusters of gastroenteritis linked to consumption of oysters from a different area of Brittany (2) occurred in weeks four to seven, involving 45 cases. Cases and oysters from the area were tested and norovirus was confirmed. Norovirus GGI and GGII were detected in the stool samples of cases whereas the results confirming the genogroup of the norovirus positive oysters are still pending. The identified harvesting areas were closed and shellfish from these areas was recalled from the market. The measures were implemented from week seven to nine.

\section{Sweden}

Fourty-eight persons in 15 clusters developed acute gastroenteritis after having eaten oysters at a restaurant in Stockholm. Two additional persons ate oysters at another restaurant in Stockholm and also developed acute gastroenteritis. Oysters were consumed between December 2009 and early March 2010. The first restaurant served both Dutch and French oysters. No stool samples were taken from the 50 cases.

\section{Denmark}

Twenty-seven norovirus cases in six clusters who had consumed oysters at three different restaurants were reported from January to March 2010. Norovirus GG I and II were detected in stool samples from two of the cases. Norovirus GG II was detected in the stool sample of a third case. Oysters served at the restaurants originated from four coastal locations in France. Oysters from all four batches tested positive for norovirus GG I and II and were recalled from the Danish market. Three RASFF alerts were issued on 12 March and a fourth alert was recently submitted. Three additional clusters, bringing the number to nine, are currently being investigated.

\section{TABLE}

Norovirus clusters linked to consumption of oysters, United Kingdom, Norway, France, Sweden and Denmark, January to March, $2010(\mathrm{n}=65)$

\begin{tabular}{|c|c|c|c|c|c|c|}
\hline \multirow{2}{*}{ Country } & \multirow{2}{*}{ Clusters } & \multirow{2}{*}{ Verified } & \multirow{2}{*}{$\begin{array}{l}\text { Total number of } \\
\text { cases }\end{array}$} & \multicolumn{2}{|c|}{ NoV detection (genogroup) } & \multirow{2}{*}{ Origin of oysters } \\
\hline & & & & Cases & Oysters & \\
\hline $\begin{array}{l}\text { United Kingdom (England and } \\
\text { Wales) }\end{array}$ & 22 & 3 & 120 & $+(\mathrm{I}, \mathrm{II})$ & $+(\mathrm{I}, \mathrm{II})$ & $\begin{array}{l}\text { England, Scotland and } \\
\text { Ireland }\end{array}$ \\
\hline Norway & 8 & 8 & 39 & NA & $+(\mathrm{I}, \mathrm{II})$ & Brittany, France \\
\hline France (1) & 6 & 6 & 22 & NA & + & Brittany, France \\
\hline France (2) & 4 & 4 & 45 & $+(\mathrm{I}, \mathrm{II})$ & + & Brittany, France \\
\hline Sweden & 16 & 0 & 50 & NA & NA & The Netherlands and France \\
\hline Denmark & 9 & 6 & 58 & $+(\mathrm{I}, \mathrm{II})$ & $+(\mathrm{I}, \mathrm{II})$ & Different locations in France \\
\hline
\end{tabular}

NA; Not available 


\section{Discussion}

This paper describes several outbreaks of gastroenteritis caused by norovirus occurring simultaneously in several European countries. Norovirus of both GG I and II were detected in oysters and in stool samples collected from cases in the outbreaks. This is a common finding in oyster-related outbreaks and reflects an environmental source of contamination [5, 14-16]. Bon et al. (2005) found up to seven different strains of norovirus in some outbreaks. This contrasts with personto-person transmission occurring in settings such as hospitals or nursing homes, which most often involve a single genotype.

It is likely that current reports underestimate the true burden of norovirus infection in the community following consumption of oysters as restaurant-associated outbreaks are more commonly reported to public health authorities than outbreaks occurring in a household setting.

Even though norovirus contamination in oysters is a known source of gastrointestinal outbreaks, the number of such events in the first three months of 2010 is considered unusual in several of the involved countries and is above what is normally observed at EU level. This increase may be due to several factors. Firstly, it could partly be a surveillance artefact as the sharing of information regarding norovirus outbreaks through the FWD network is relatively recent and may have contributed to the reporting of these events. There is currently no evidence to suggest that the increase in reported outbreaks is due to increased transmission in the EU population. Norovirus activity in the current season appears to be higher than in recent years in Norway and the UK whereas France and Sweden did not observe a similar pattern. Secondly, as the contamination of the oyster harvesting areas is not restricted to a single location, it would indicate a broader environmental issue and not a localised contamination problem. It is possible that the unusually cold winter experienced in northern Europe during the first three months of 2010 favoured the contamination

\section{FIGURE}

Epidemic curve by week of onset of reported cases from Norway, France, Sweden and Denmark, December 2009 to March $2010(\mathrm{n}=183)$

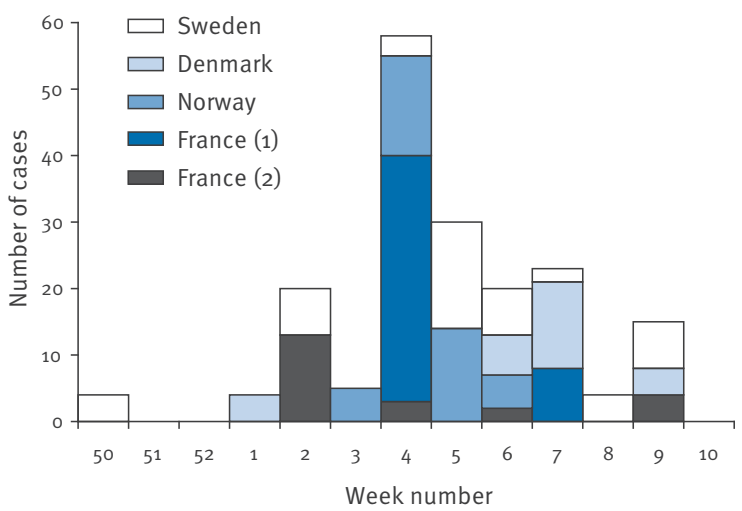

of the oysters as virus survival increases in cold water temperatures and reduced exposure to ultraviolet light [17].

In conclusion, an increased number of norovirus outbreaks related to the consumption of oysters have been observed at EU level in the last three months. The reason for this needs to be further investigated. With the expected decline both in the seasonal activity of norovirus and the seasonal consumption of oysters in Europe over the next coming month(s) it is likely that reports about outbreaks such as the ones described here will also decrease. However, consuming raw oysters involves potential exposure to norovirus and is particularly hazardous for immunocompromised or chronically ill persons. Therefore, countries might consider informing the public about the risks linked with consuming raw oysters. Furthermore, it is important that countries continue to notify these events through the RASFF in order for producers to be informed in a timely manner about contamination, enabling them to implement control measures.

\section{Acknowledgements}

We would like to acknowledge the work performed in the outbreak investigation teams in the involved countries.

French team: Y Guillois-Becel, French Institute for Public Health Surveillance, Bretagne region; K Balay, National Reference Center for Enteric viruses, Dijon; J-C Le Saux and S le Guyader, French Research Institute for Exploitation of the Sea Ifremer, Nantes and Brest; G Delmas, French Institute for Public Health Surveillance, Paris; N Pihier, H Callon and S Salah, Ministry of Agriculture, Paris.

Danish team: B Böttiger, Statens Serum Institut; A C Schultz, National Food Institute; S Jespersen, S Olsen, D Grausen, C Møller, A Peschardt, Regional Veterinary and Food Control Authority East; A Mariager, Danish Veterinary and Food Administration.

Norwegian team: Elin Osborg, The Norwegian Food Authority, Oslo; Mette Myrmel, The Norwegian School of Veterinary Science, Oslo; Karin Nygård, National Institute of Public Health, Oslo

Swedish team: M Edlund, Environmental Health office, Stockholm.

\section{References}

1. Burkhardt W, 3rd, Calci KR. Selective accumulation may account for shellfish-associated viral illness. Appl Environ Microbiol. 2000;66(4):1375-8.

2. Boxman IL, Tilburg II, Te Loeke NA, Vennema H, Jonker K, de Boer $E$, et al. Detection of noroviruses in shellfish in the Netherlands. Int J Food Microbiol. 2006;108(3):391-6.

3. Costantini V, Loisy F, Joens L, Le Guyader FS, Saif LJ. Human and animal enteric caliciviruses in oysters from different coastal regions of the United States. Appl Environ Microbiol. 2006;72(3):1800-9.

4. Gentry J, Vinje J, Guadagnoli D, Lipp EK. Norovirus distribution within an estuarine environment. Appl Environ Microbiol. 2009;75(17):5474-80.

5. Le Guyader FS, Bon F, DeMedici D, Parnaudeau S, Bertone A, Crudeli S, et al. Detection of multiple noroviruses associated with an international gastroenteritis outbreak linked to oyster consumption. J Clin Microbiol. 2006;44(11):3878-82.

6. Berg DE, Kohn MA, Farley TA, McFarland LM. Multi-state outbreaks of acute gastroenteritis traced to fecal-contaminated oysters harvested in Louisiana. J Infect Dis. 2000;181 Suppl 2:S381-6. 
7. McLeod C, Hay B, Grant C, Greening C, Day D. Inactivation and elimination of human enteric viruses by Pacific oysters. J Appl Microbiol. 2009;107(6): 1809-1818

8. Doyle A, Barataud D, Gallay A, Thiolet JM, Le Guyaguer S, Kohli E, Vaillant V. Norovirus foodborne outbreaks associated with the consumption of oysters from the Etang de Thau, France, December 2002. Euro Surveill. 2004;9(3). pii=451. Available online: http://www.eurosurveillance.org/ViewArticle. aspx?Articleld $=451$.

9. Le Guyader FS, Le Saux JC, Ambert-Balay K, Krol J, Serais 0 , Parnaudeau S, et al. Aichi virus, norovirus, astrovirus, enterovirus, and rotavirus involved in clinical cases from a French oyster-related gastroenteritis outbreak. J Clin Microbiol. 2008;46(12):4011-7.

10. Nenonen NP, Hannoun C, Olsson MB, Bergstrom T. Molecular analysis of an oyster-related norovirus outbreak. J Clin Virol. 2009;45(2):105-8.

11. Baert L, Uyttendaele M, Stals A, van Coillie E, Dierick K, Debevere J, et al. Reported foodborne outbreaks due to noroviruses in Belgium: The link between food and patient investigations in an international context. Epidemiol Infect. 2009;137(3):316-25.

12. Lowther JA, Henshilwood K, Lees DN. Determination of norovirus contamination in oysters from two commercia harvesting areas over an extended period, using semiquantitative real-time reverse transcription PCR. J Food Prot. 2008;71(7):1427-33.

13. Miossec L, Le Guyader F, Haugarreau L, Pommepuy M. [Magnitude of rainfall on viral contamination of the marine environment during gastroenteritis epidemics in human coastal population]. Rev Epidemiol Sante Publique. 2000;48 Suppl 2:2S62-71. [French].

14. Bon F, Ambert-Balay K, Giraudon H, Kaplon J, Le Guyader S, Pommepuy M, et al. Molecular epidemiology of calicivirases detected in sporadic and outbreak cases of gastroenteritis in France from December 1998 to February 2004. J Clin Microbiol. 2005;43(9):4659-64.

15. Gallimore Cl, Cheesbrough JS, Lamden K, Bingham C, Gray JJ. Multiple norovirus genotypes characterised from an oysterassociated outbreak of gastroenteritis. Int J Food Microbiol. 2005;103(3):323-30.

16. Symes SJ, Gunesekere IC, Marshall JA, Wright PJ. Norovirus mixed infection in an oyster-associated outbreak: An opportunity for recombination. Arch Virol. 2007;152(6):1075-86.

17. Duizer E, Bijkerk P, Rockx B, De Groot A, Twisk F, Koopmans M. Inactivation of caliciviruses. Appl Environ Microbiol. 2004;70(8):4538-43. 